\title{
Design of a Tri-band Slotted Circular Microstrip Antenna with Improved Bandwidth for Wideband Applications
}

\author{
N. L. Vamsi Priya.K ${ }^{1}$, P. Pratyusha ${ }^{2}$ and K. Jagadeesh Babu ${ }^{3}$ \\ ${ }^{1,2}$ Asst. Professors, Dept of ECE, SACET, Chirala, AP, India \\ ${ }^{3}$ Professor \& HOD, Dept of ECE, SACET, Chirala, AP, India \\ priyakece@gmail.com,pratyu2mail@gmail.com
}

\begin{abstract}
This paper presents a tri-band rectangular slotted circular micro strip antenna for wideband applications. The antenna operates at 2.96, 6.42 and $7.33 \mathrm{GHz}$ frequency bands for VSWR $<1$ with an improved impedance bandwidth of $41.23 \%$. The antenna has been designed and simulated on an FR4 substrate with dielectric constant $\left(\varepsilon_{r}\right)$ of 4.4 with an overall size of $50 \times 40 \times 3.5 \mathrm{~mm}^{3}$. The study of bandwidth improvement is presented in this paper by introducing the slots on surface of circular patch. The measured bandwidths for $-10 \mathrm{~dB}$ reflection coefficient are $410 \mathrm{MHz}(2.80-3.21 \mathrm{GHz})$ and $3.07 \mathrm{GHz}(5.91-8.98$ $\mathrm{GHz}$ ). The simulated results show that the proposed antenna provides good performance in term of return loss and radiation pattern for wideband applications.
\end{abstract}

Keywords: Tri-band, Patch antenna, Bandwidth improvement, Return loss, Radiation pattern

\section{Introduction}

Microstrip patch antennas have been worked out extensively due to the advantages of compactness, light weight, and easiness to fabricate [1] however micro strip antennas suffer from an inherent limitation of narrow impedance bandwidth. Researchers have offered numerous methods like aperture coupling [2], stacked patch [3], modifications in the feed [4], staggering effect [5] to enhance the bandwidth of microstrip antennas [6]. However all these techniques make the design of the antenna more complex. Recently, tri-band antennas gained attention as they can be used for various applications including Wi-Max [7].

In the present work, a Tri-band Slotted Circular Micro strip Antenna [8] is proposed. This antenna resonates at 2.96, 6.42 and $7.33 \mathrm{GHz}$, which can be used for wideband [9] applications. In section 2, the proposed antenna geometry and the effect of introducing slots [10] on the proposed antenna are discussed and in section 3, the simulation results are presented.

\section{Antenna Design}

The design of the antenna begins with a circular micro strip antenna with patch radius $12 \mathrm{~mm}$. The substrate chosen for the proposed antenna is FR-4 epoxy with dielectric constant, $\varepsilon_{r}=4.4$ and a thickness of $3.5 \mathrm{~mm}$. Three rectangular slots with sizes of $16.5 \mathrm{~mm}$ $\times 1 \mathrm{~mm}$ and $11 \mathrm{~mm} \times 1 \mathrm{~mm}$ and $6 \mathrm{~mm} \times 1 \mathrm{~mm}$ were made on the circular patch antenna. The dimensions of the substrate are taken as $50 \times 40 \times 3.5 \mathrm{~mm}^{3}$ and the size of the ground plane is taken as $50 \times 40 \mathrm{~mm}^{2}$. The geometry of proposed microstrip patch antenna is shown in Fig 1. All the dimensions are in mm. 


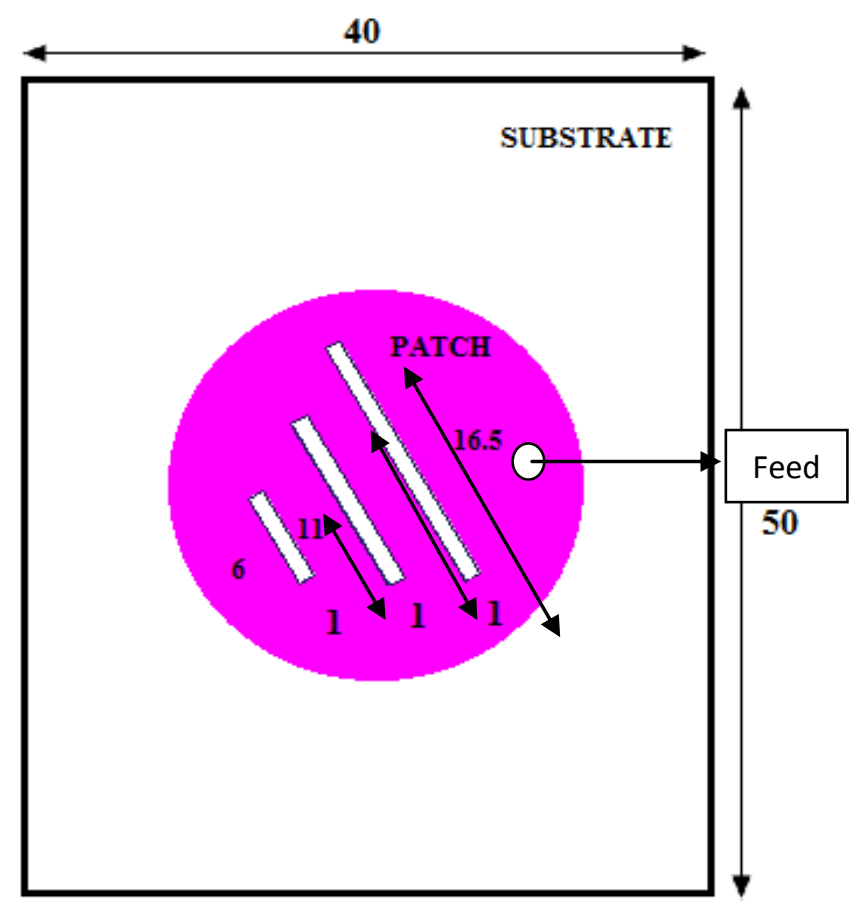

(a)

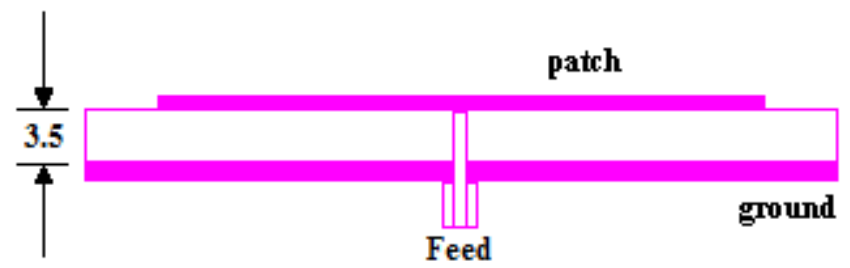

FR4 Substrate

(b)

Figure 1. Proposed Microstrip Patch Antenna (a) Top View (b) Side View

Microstrip patch antennas can be fed by a variety of methods. These methods are classified into two categories which are contacting (direct) and non-contacting. The four most popular feeding techniques used are microstrip feed; co-axial probe feed, aperture coupled and proximity coupled feeding. Here the whole system is fed by a co-axial probe.

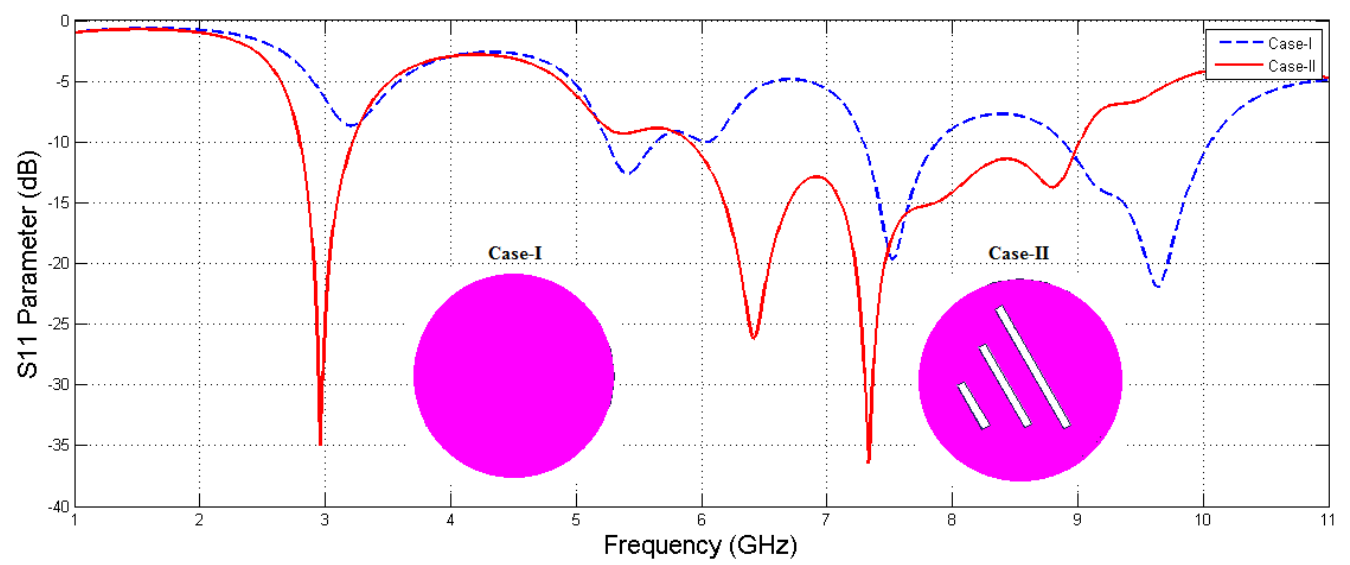

Figure 2. The Effect of Introducing Slots on the Proposed Antenna 
Initially we consider the circular microstrip patch antenna without any slots. It has very poor performance in terms of bandwidth and return loss. It is considered as case1. By introducing the rectangular slots on the circular microstrip patch antenna the tri-band is achieved with bandwidth of $3.07 \mathrm{GHz}$ including middle and upper bands. The effect of introducing these slots on the proposed antenna is shown in Figure 2.

\section{Results}

The simulation results for the proposed antenna are shown in the figures below. The return loss is shown in Figure 3. The antenna resonates at frequency 2.96, 6.42 and 7.33 $\mathrm{GHz}$ with a return loss of $37.24 \mathrm{db}, 25.50 \mathrm{db}$ and $38.99 \mathrm{db}$ respectively. The measured bandwidths for $-10 \mathrm{~dB}$ reflection coefficient are $410 \mathrm{MHz}(2.80-3.21 \mathrm{GHz})$ and $3.07 \mathrm{GHz}$ (5.91-8.98 GHz). The VSWR plot is shown in Figure 4. The VSWR values are 0.23, 0.92 and 0.24 for corresponding three resonant frequencies indicating the good matching conditions with triple band frequencies. The radiation patterns at $2.96,6.42$ and $7.33 \mathrm{GHz}$ for $\quad \dot{\varnothing}=0^{0} \& 90^{\circ}$ are shown in Figure 5.

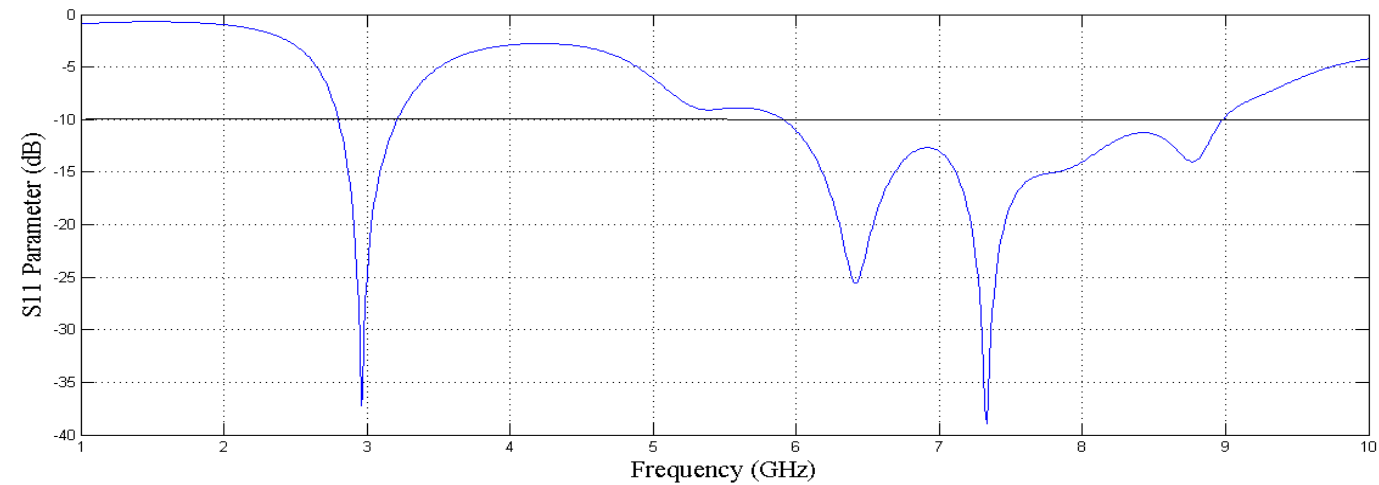

Figure 3. Return Loss of the Proposed Antenna

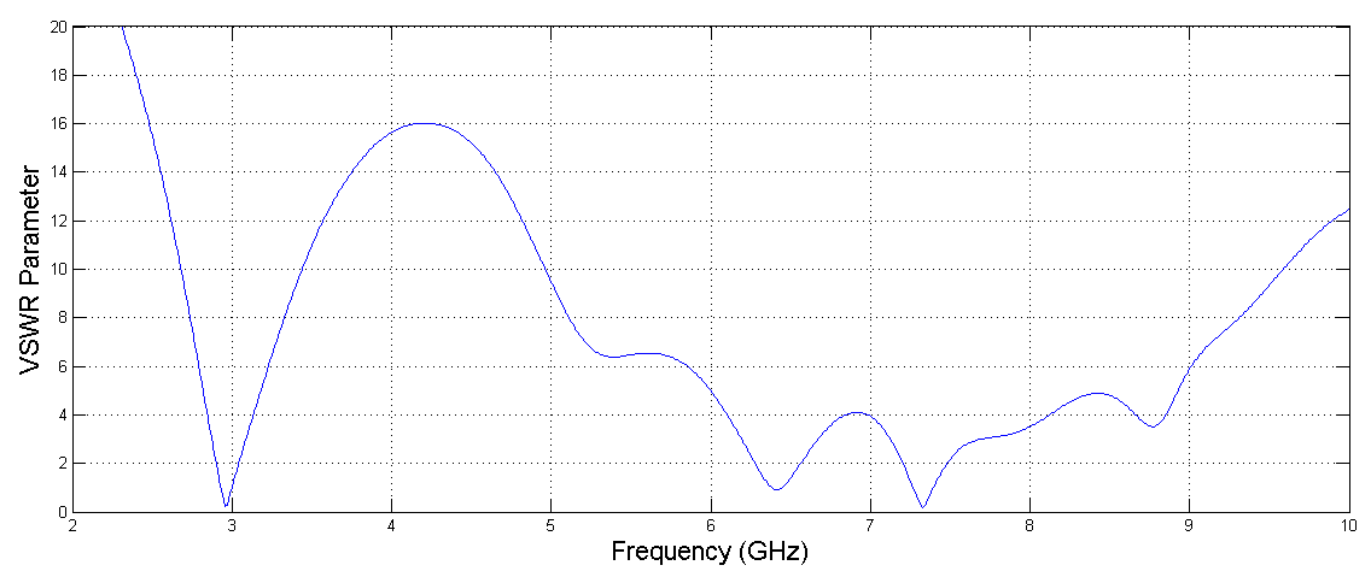

Figure 4. VSWR Plot of the Proposed Antenna 


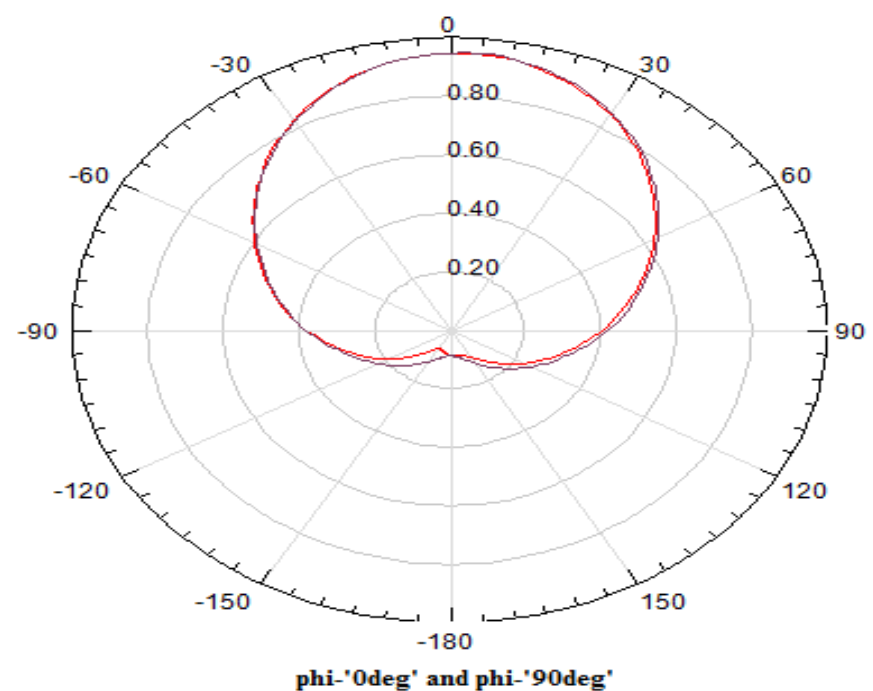

a) Radiation pattern at $2.96 \mathrm{GHz}$

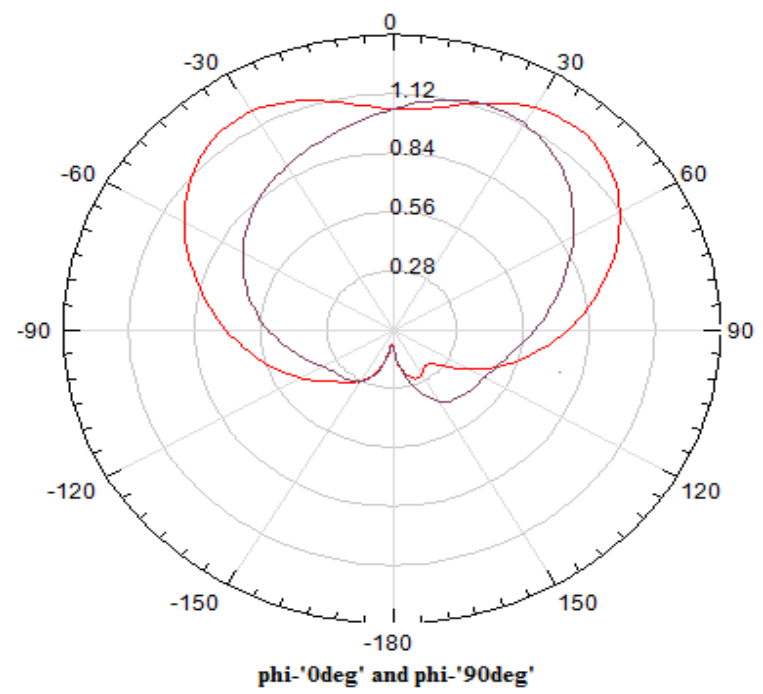

b) Radiation pattern at $6.42 \mathrm{GHz}$

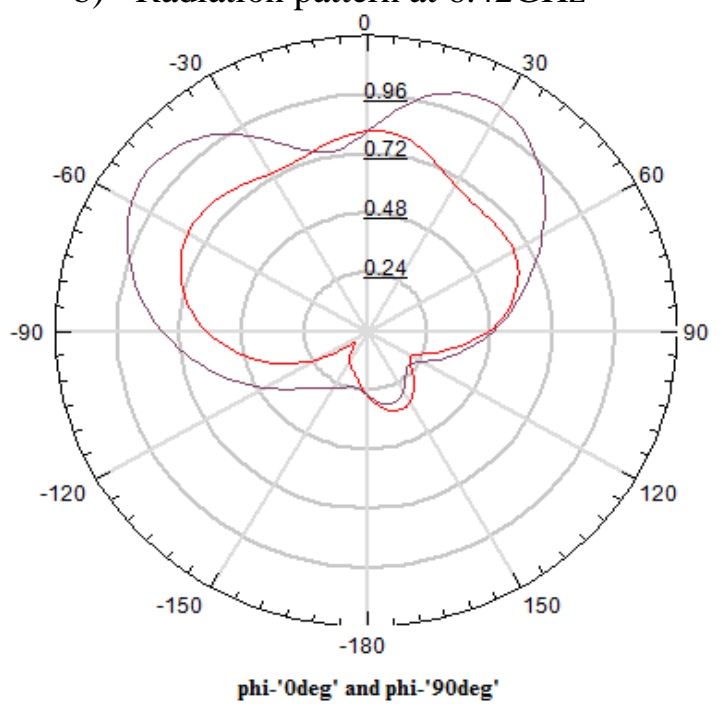

c) Radiation Pattern at $7.33 \mathrm{GHz}$

Figure 5. Radiation Patterns of the Proposed Antenna 


\section{Conclusion}

This paper presents a tri-band slotted circular microstrip antenna for wideband applications. The proposed antenna has a compact size of $50 \mathrm{~mm} \times 40 \mathrm{~mm}$. The antenna operates at 2.96, 6.42 and $7.33 \mathrm{GHz}$ frequency bands for VSWR $<1$ with an improved impedance bandwidth of $41.23 \%$. The study of bandwidth improvement is presented in this paper by introducing the slots on surface of circular patch. The simulated results show that the proposed antenna provides good performance in term of return loss and radiation pattern for wideband applications.

\section{References}

[1] C. A. Balanis, "Antenna theory analysis and design", 2nd edition, John Wiley \& sons, Inc., (1997).

[2] J. R. James and P. S Hall, "Handbook of microstrip Antennas" Peter Peregrinus Ltd, London, vol. 2, (1989).

[3] I. J. Bahl and P. Bhartia, "Microstrip Antenna" Artech House, (1980).

[4] C. H. Lai, T. Y. Han and T. R. Chen, "Broadband aperture-coupled microstrip antennas with low cross polarization and back radiation", Progress In Electromagnetic Research Letters, vol. 5, (2008), pp. 187197.

[5] Z. Nasimuddin and N. Chen, "Wideband microstrip antennas with sandwich substrate", IET Microwaves, Antennas \& Propagation, vol. 2, (2008), pp. 538-546.

[6] D. M. Pozar and D. H. Schaubert, "Microstrip Antennas", New York: IEEE Press, (1995).

[7] K. J. Babu, K. S. R. Krishna and L. P. Reddy, "A triband swastika shaped patch antenna with reduced mutual coupling for wireless MIMO systems", Journal of Electronics (China), SPRINGER, vol. 28, (2011) November, pp. 483-487

[8] K. Mandal, S. Sarkar, and P. P. Sarkar, "Bandwidth enhancement of microstrip antenna by staggering e®ect", Microwave and Optical Technology Letters, vol. 53, (2011), pp. 2446-2447.

[9] M. T. Ali, N. Nordin, N. Ya'acob, and M. N. Md. Tan, "Design of wideband microstrip patch antenna using L probe fed at $2.6 \mathrm{GHz}$ ", International Conference on Communication and Computer Engineering, $961\{965$, IEEE, Kuala Lampur, (2012) July 3-5.

[10] J.-Y. Jan and J.-W. Su, "Bandwidth enhancement of a printed wide-slot antenna with a rotated slot", IEEE Trans. Antennas Propag., vol. 53, no. 6, (2005), pp. 2111-2114.

\section{Authors}

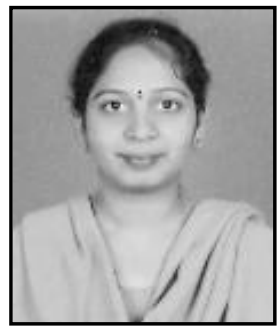

N. L. Vamsi Priya K, she received her B. Tech. degree in Electronics and Communication Engineering in 2005 from JNTU Hyderabad, India and M. Tech. Degree in VLSI Systems JNTU Kakinada, India in 2012. She is presently working as Assistant Professor at SACET, JNTUK, Chirala. Her areas of interest include VLSI, Microstrip Antennas, MIMO Antennas, and Wireless communications.

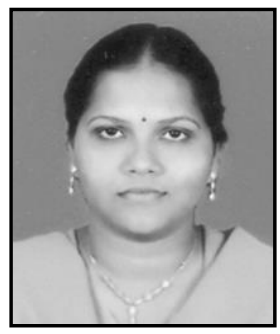

Pratyusha Pushadapu, she received her B.Tech degree in Electronics and Communication Engineering in 2008 from the JNTU Hyderabad and M. Tech degree in VLSI system Design from JNTUH in 2012. She is presently working as Assistant Professor at SACET, Chirala. Her areas of interest include VLSI, Antennas. 


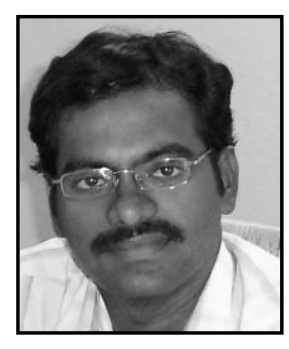

Kamili Jagadeesh Babu, he is working as Professor \& HOD in E.C.E Department, at St. Ann's College of Engineering \& Technology, Chirala, India. He obtained his Ph.D. degree from Jawaharlal Nehru Technological University Hyderabad, Hyderabad, India in 2013. His areas of interest include design of Microstrip and Dielectric Resonator Antennas for MIMO applications and UWB antennas for wireless applications. He published more than 20 research papers in referred journals. He is currently a reviewer for many journals such as ACES, International Journal of Electronics Letters (Taylor \& Francis), RPST, etc. He is a Member of IEEE. 